\title{
Fundamental policy challenges influencing sustainable development in Africa
}

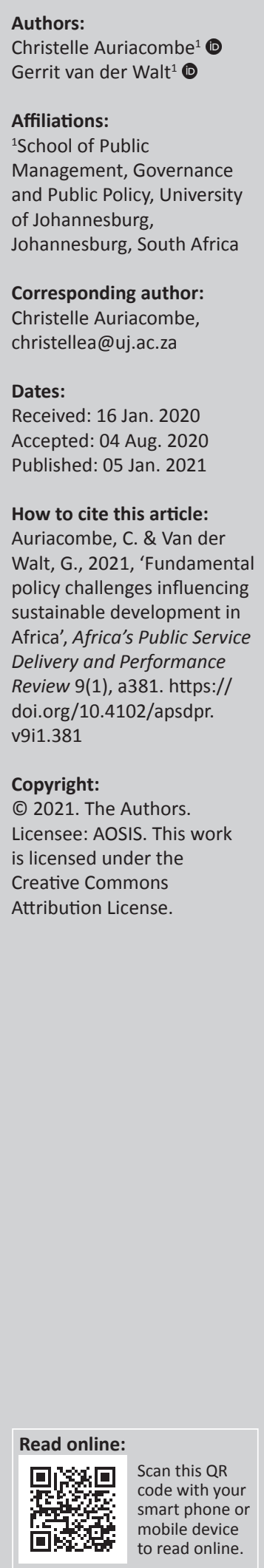

Background: There is widespread recognition on the African continent that a coherent and integrated policy response is necessary to adequately deal with issues associated with sustainable development. Despite this general recognition, it is, however, also evident that much still needs to be done to realise a coherent policy response fostered by a transgovernance approach to sustainable development.

Aim: The aim of this article is to analyse the nature and scope of development policy influencing Africa's policy responses to sustainable development challenges.

Setting: Challenges associated with sustainable development transcend national borders. This requires trans-border policy responses and transgovernance. Transgovernance goes beyond conventional governance approaches and moves towards a more integrated global and continental response to address sustainability issues. The same applies to Africa as a continent.

Methods: In the traditions of interpretivism, the methodology is based on a desktop analysis by means of a literature survey. The qualitative description of the findings focuses on the themes that emerge from the research and the manner in which it was conceptualised and contextualised in terms of unobtrusive research techniques.

Results: Results indicate that across Africa there have been varied policy responses to sustainable development challenges. It was established that despite successes on the continent, inclusive of the establishment of various sectoral policy frameworks and coordinating mechanisms, there is still great concern for the general lack of a coordinated response to environmental concerns. Change in policy-making approaches and practices as well as changes in attitudes towards the environment are essential.

Conclusion: Policy coherence on the continent is a prerequisite to promote sustainable development. Policy responses need to consider the finite nature of natural resources and the future implications of current government actions (and inactions). Policy-makers need to look forward, contemplating the interrelationship between human-driven development and the environment, and approach policy design in a fundamentally new way.

Keywords: Africa; development; sustainable development; policy; policy coherence; policy response; transgovernance.

\section{Introduction}

Africa's development policies are typically implemented by means of national development plans. For many countries, these national development plans were largely 'state-based' (cf. Chibber 2014; Kerbo 2006), meaning that it did not adequately consider regional challenges and realities. However, more recently there is growing awareness that individual countries simply do not have the required capacity and competency to address cross-border and regional development challenges such as climate change, water supply, infrastructure development and disease. International and regional co-operation and co-ordination of efforts are thus essential to address such challenges. International treaties, protocols, conventions and agreements generally guide such co-operation and co-ordination endeavours. A further challenge as far as continental development challenges are concerned is the fact that most African countries are heavily dependent on exploiting natural resources to fund their national development efforts (cf. Grin, Rotmans \& Schot 2010). This has generally led to severe resource depletion and environmental degradation. It also made countries more vulnerable to external shocks that weakened their economies even further. This, in turn, has limited the capacity of individual states to address chronic poverty and to address broad-based challenges associated with socio-economic development. 
As a result of poor economic growth, a significant number of African countries embarked upon Structural Adjustment Programmes (SAPs) during the 1980s and 1990s and Poverty Reduction Strategies (PRSs) from 1999. Structural Adjustment Programmes were mainly World Bank and International Monetary Fund-driven. In South Africa, the SAPs were called the 'Reconstruction and Development Programme' (RDP). The SAPs were mainly aimed at correcting macroeconomic imbalances that had occurred as a result of statecontrolled economic policies. These programmes should be viewed against the backdrop of the highly indebted poor countries initiative (HIPC). Unfortunately, because of this, the PRSs did not adequately incorporate environmental and social sustainable development concerns. Furthermore, the SAPs and PRSs were generally not successfully implemented because of limited policy coordination and the absence of clear responsibilities and ownership. Policies had contradictory sectoral impacts because they were not aligned and co-ordinated by the respective countries (Meadowcroft 2007). Furthermore, there were limited strategies and policies in place to co-ordinate endeavours in various sectors such as agriculture, industry and social welfare to generate significant economic value and employment to eradicate poverty.

On the positive side of the coin, it is noteworthy that countries are learning from past experiences and have moved towards the so-called 'second generation' of PRSs (Driscoll et al. 2007). The second-generation policies are more integrated, aligned and adequately broad-based to address sustainable development concerns. This is an important shift in focus seen in the context of meeting development targets specified in the post-2015 Sustainable Development Goals. These new policies are also aimed at accelerated economic growth to generate adequate income for the funding of development programmes. It remains to be seen whether these secondgeneration policies will yield the desired results and whether it will integrate environmental sustainable development concerns with economic and social programmes aimed at addressing inequalities and poverty.

It has become crucial for governments to find ways of managing these demands efficiently. Governments have to regulate development initiatives to protect the environment and, simultaneously, also promote economic prosperity. This delicate role of government in sustainable development by creating adequate sectoral and national policy frameworks and strategic approaches is the main focus of this article.

\section{Sustainable development policy in perspective}

It is commonly accepted that sustainable development primarily comprises three core dimensions, namely, economic, social and environmental (cf. Purvis, Mao \& Darren 2018:682). These dimensions gave rise to the need for international, continental, regional, national and institutional policies to perform certain key roles, namely:
- An economic role, to build vibrant and competitive economic infrastructure and systems to enhance economic growth and prosperity

- A social role, to foster vibrant communities through housing, responsive service delivery, education, health services, poverty alleviation and general well-being

- An environmental role, to protect and enhance the natural and human-made environment through improving biodiversity, the efficient utilisation of resources, the minimisation of waste and pollution and cleaner energy.

Scholars of governance often regard the policy-making function of government as its primary responsibility. The concept of policy is used in many fields of activity such as social policy, environmental policy, economic policy, foreign policy and so forth. Policy can thus be regarded as the instrument for the maintenance and improvement of human welfare by focusing on problem solutions by the legislative authorities of government through the allocation of resources (Birkland 2005:5). Theorists of public policy, such as Dye (1995:3) and Anderson (2000:4), further agree that policies act as parameters or frameworks within which all societal dynamics are directed. This includes the regulation of sustainable development dimensions, inclusive of economic growth, education, healthcare, and the general prosperity and well-being of society.

\section{Development policy levels}

Scholars generally concur that development policy can be examined on four levels (Anderson 2000:14; Dye 1995:13; eds. Voß, Bauknecht \& Kemp 2006:22). The following four levels can be distinguished:

- Political policy or party political policy: This refers to policy of a political party. When a particular party becomes the ruling party, its policies will also become the policy (i.e. national legislation) of the country. One should note, however, that national policy should preferably be the result of robust and healthy debates in portfolio committees and parliament rather than 'the-winnertakes-all' approach often seen in some African countries. The dominant ideology, as well as coalition politics, may further influence political policy.

- Government or national policy: National policy (i.e. statutes and legislation) is generally the translation of the ruling party's political policy into more practical and sector-specific expressions of how the country will be governed and its specific development ideas and strategies.

- Executive policy: Government policy is usually made by the political heads (i.e. democrats) of government departments in conjunction with senior public officials (i.e. technocrats). Each department will design policies associated with its specific sphere of function and as mandated by the constitution and the legislative authority. The Department of Health of a country, for example, will design national legislation dealing with health issues and translate that into departmental policies to guide official action (i.e. health programmes and educational projects). 
- Operational or administrative policy: Operational or administrative policy is the lowest level of policy and refers to very specific policies to translate departmental (executive) policy into the day-to-day operations of public officials. Operational guidelines and procedures are usually developed to further assist officials to effectively interpret these policies. Operational policies include the way staff should be managed (e.g. recruitment, appointment, career development, promotion and so on) and how finances are utilised (e.g. procurement, salaries, tender procedures, accounting, auditing and so on).

Especially government or national policy, as it relates to continent-wide sustainable development, is the focus of this article.

\section{Policy-making process}

There is a typical process associated with the design of policy. The scope of the process followed, the nature of resources utilised and the number of institutions and agencies involved will depend on the institutions (e.g. development agencies) involved in the policy-making process. In a sustainable development context, policy can thus be designed by:

- international development and donor aid agencies, thus policy with a global scope

- continental governance bodies such as the African Union, thus policy with a continental scope

- regional institutions such as the Southern African Development Community (SADC), thus policy with a regional scope

- national government agencies, thus policy with a national scope.

Policy is intended to direct actions - to enable and mandate executive institutions to address a particular societal problem. Similarly, policies associated with sustainable development need to be designed to deal with its social, economic and environmental dimensions and issues. For purposes of illustration, national policy (i.e. statutes of Parliament or legislation) typically follows incremental phases in designing, formulating, implementing and evaluating policy. According to authors such as Stone (2001:56), Birkland (2005:71), and Moran, Rein and Goodin (eds. 2008:44), these phases typically include the following:

- Phase 1 - Identification of the particular policy problem: In this first phase an issue is recognised and analysed to pinpoint its underlying causes.

- Phase 2 - Policy agenda: Once the particular problem is identified and recognised as important enough to warrant government action, political parties, interest groups or individuals will bring it to the attention of political representatives. Media reports, petitions, protests and direct contact with representatives are generally used to place an issue under government's attention. If politicians acknowledge the gravity and severity of the situation, they will prioritise action accordingly.
- Phase 3 - Formulation of a proposal: Once the issue features on the political agenda, a particular portfolio committee will be appointed to investigate alternatives to dealing with the issue. After careful consideration and after gaining input from interest or specialist groups, the committee will formulate a particular proposal that outlines the best alternative course of action to address the issue.

- Phase 4 - Policy adoption: The portfolio committee will table the proposal (usually in the form of a 'Green Paper') in parliament to enable further deliberations. The proposal will then be translated into a 'White Paper'. After further deliberations, the White Paper will become a 'Bill' and once signed by the president, it becomes an 'Act' of parliament (i.e. national legislation).

- Phase 5 - Policy implementation: National legislation needs to be implemented to address the identified issue. Specific government departments or agencies will be tasked to make the necessary organisational arrangements to successfully translate policy into action. Resources will be made available and managers need to plan, strategize, control, monitor and guide action to effectively and efficiently implement policies.

- Phase 6-Policy evaluation and analysis: The last phase in the policy-making process is the evaluation of the policy to gauge its efficiency and effectiveness to deal with the identified issue. During implementation, pre- and postanalyses are necessary to determine the outcomes and impact of the policy in the short, medium and long term. Monitoring mechanisms also need to be established to ensure that policy has the intended effect and to enable proactive corrective action.

This concludes a brief exposition of the basics of public policy. The next section explores the policy responses of African countries to deal with the social, economic and environmental dimensions of sustainable development.

\section{Policy responses to Africa's development challenges}

Scientific inquiry into appropriate policy responses to sustainable development is largely informed by Earth Systems Analysis (ESA) (ed. Brauch 2012:11). Earth Systems Analysis is especially useful to guide policy debates towards cleaner energy and green growth. In 2009, the Sustainability Transitions Research Network (STRN 2009) was established to focus on sustainability challenges in all major sectors of society, such as energy, water, food security and transport. This network further led to a more integrated and multidisciplinary approach to sustainable development by incorporating theories, such as complexity theory, innovation theory, path dependency theory, change management theory and governance theory. This significantly improved the body of knowledge associated with sustainable development and further informed economic and social transitions in countries (ed. Brauch 2012:11; Grin et al. 2010). 


\section{Sustainable development policy dimensions}

From a policy response point of view, Brauch (ed. 2012:14-24) elaborates on the following seven policy dimensions of sustainable development:

- Temporal: focuses on the relatively long-term (e.g. several decades) outcomes and impact of policy approaches to sustainable development. These policy approaches are influenced by other dimensions in society that are in a constant state of flux, such as political dynamics, the system of government, and technological advancement.

- Spatial: focuses on the scope and scale of issues, such as geographical and regional realities of countries. Policies should accommodate these realities to ensure their successful implementation.

- Scientific: focuses on scientific and technological knowledge to support policy design. The use of earth data, demographical statistics, and environmental data bases is crucial to base policy responses to scientific evidence. Software models are further extremely useful to plot long-term trends, e.g. the so-called 'butterfly effects', where small initiatives end up generating surprisingly large effects.

- Societal: focuses on the so-called 'soft' dimensions of development, such as the wishes, aspirations, attitudes, opinions, needs, mind-sets, behaviour, and priorities of people.

- Economic: focuses on international markets, investment in cleaner energy, the green economy and renewable resources.

- Political: focuses on governance structures and systems, democratic practices, policy-making dynamics, international collaboration and sectoral alignment for policy implementation.

- Cultural: focuses on values, belief systems, ideologies, ethics, and morals that influence policy-making processes, as well as the legitimacy of certain policy responses.

As indicated earlier, challenges associated with sustainable development transcend national borders. This requires trans-border policy responses and 'transgovernance' (Veld 2011:xv in ed. Brauch 2012:22). Transgovernance goes beyond conventional governance approaches and moves towards a more integrated global response to address sustainability issues. The same applies to Africa as a continent.

A literature review reflects that there is widespread recognition on the African continent that a coherent and integrated policy response is necessary to adequately deal with issues associated with sustainable development. It is further evident that countries generally acknowledge the need to establish a conducive environment in all spheres of government to support sustained economic growth, social well-being and environmental protection. In all of this, good governance is a prerequisite. Despite this general observation, it is, however, also evident that much still needs to be done to realise sustainable development policy objectives. If governments do not create the necessary policy design and implementation capacity to deal with pressing challenges, it could have a detrimental impact on future generations. For example, the pollution of water supplies, deforestation and the use of firewood for cooking, agricultural growth and the overutilisation of marine life may lead to negative consequences for the environment.

Across Africa there have been varied policy responses to sustainable development challenges (Voß et al. 2006). These policy responses also differ from the regional to the community level in particular countries. Stakeholders such as international agencies, government departments, nongovernmental organisations (NGOs), community-based organisations (CBOs) and specialist agencies all have to make contributions to design appropriate policies and to direct the successful implementation thereof. There are a number of landmark initiatives and global policy responses in this regard:

- The former Millennium Development Goals and the new post-2015 Sustainable Development Goals

- The United Nations Conference on Environment and Development (UNCED), the Rio Declaration, and Agenda 21

- The creation of the African Union and its various agencies and programmes

- The African Ministerial Conference on the Environment (AMCEN), to design collaborative approaches to environmental management

- The World Summit on Sustainable Development and the Johannesburg Plan for Implementation (JPOI)

- The Africa Convention on the Conservation of Nature and Natural Resources (ACCNNR)

- The establishment of the New Partnership for Africa's Development (NEPAD), with its respective programmes.

From an economic development point of view, NEPAD has led to initiatives promoting economic cooperation, improving global competitiveness and facilitating good corporate governance. Some of these initiatives include the establishment of economic communities on a sub-regional level. These are:

- The Southern African Development Community (SADC)

- The Economic Community of West African States (ECOWAS)

- The East African Community (EAC)

- The Economic Community of Central African States (ECCAS)

- The Intergovernmental Authority on Development (IGAD)

- The Arab Maghreb Union (AMU).

These initiatives stimulate trade on the continent by minimising limits and controls as far as the cross-border movement of citizens and products is concerned. These initiatives broadly established a coordinated and comprehensive economic policy response to sustainable 
development. These initiatives also directed political consensus on the continent in designing appropriate programmes of action and led to scientific evidence that causal relationships exist between various aspects of development. According to UNEP's African Environmental Outlook (2006), the following general aspects can be deduced from Africa's policy response:

- The recognition that a comprehensive, holistic and integrated response to sustainable development is required

- The awareness that good governance and the capacity of governments to successfully implement policies (e.g. human, financial, infrastructure and so on) are prerequisites for sustained growth and development

- General consensus that the environment is a crucial component of sustainable development

- The environment could provide much-needed prospects for economic growth (e.g. tourism and the hospitality industry), poverty alleviation (e.g. food production) and human well-being (e.g. aesthetic dimensions and recreational opportunities)

- A future orientation by considering the long-term impact of government policies

- The need to establish governance networks, and international and regional collaboration and partnerships to collectively address the continent's challenges

- The utilisation of scientific knowledge and appropriate technology to respond effectively
- The design of implementation strategies and programmes, as well as detailed operational guidelines to successfully execute policies.

To these general deductions, one may add the recognition that public participation is vital in the success of policy design and implementation. Civil society engagement, congruence with local cultures and partnerships with civil society organisations are crucial in this regard. This includes the utilisation of local knowledge systems and cultural practices. In this respect, the African Union established the Economic, Social and Cultural Council (ECOSOCC) to guide and encourage public participation in social development issues. Furthermore, the Arusha Charter on Popular Participation (1990) acknowledges the importance of civil society engagement in governance structures to frame development policies. Civil society is often regarded as the 'third' sector in a three-way partnership with the state (public sector) and business (private sector). The third sector is typically organised around specific interests of particular groups, such as religious rights, farmers' rights, women's rights, human rights, CBOs and NGOs.

\section{Policy frameworks}

The lessons learned from the policy responses mentioned above have led to the design of various sector-specific frameworks to deal with sustainable development. Figure 1,

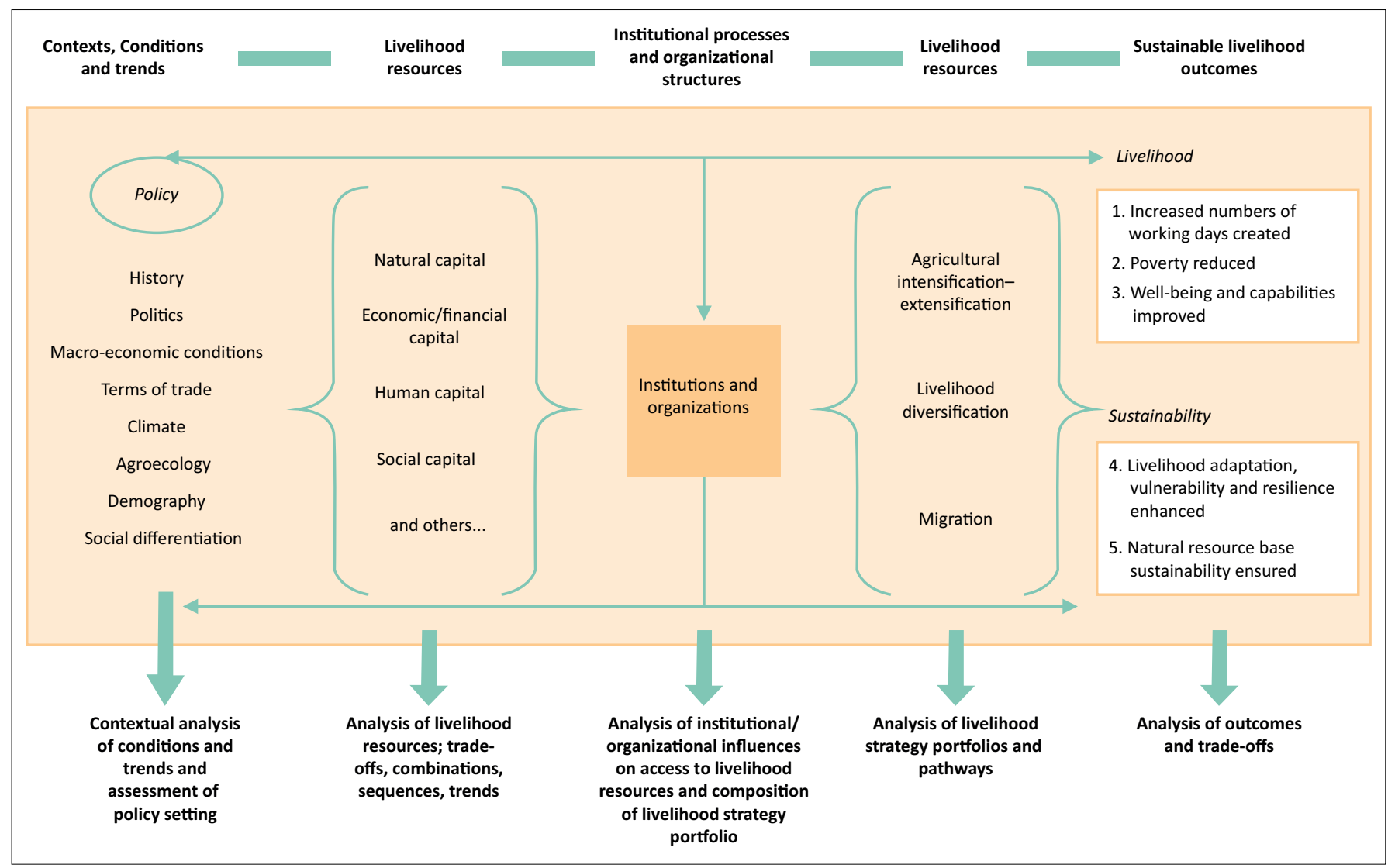

Source: Scooner, I., 1998, 'Sustainable rural livelihoods: A framework for analysis', IDS working paper, IDS, Addis Ababa.

FIGURE 1: Sustainable livelihoods framework. 
for example, illustrates such an integrated framework for sustainable livelihoods.

Similar frameworks are in place on the continent to deal with:

- climate change (e.g. United Nations Framework Convention on Climate Change)

- endangered species and organic material (e.g. Convention on Biological Diversity)

- arid regions (e.g. Convention to Combat Desertification)

- marine resources (e.g. Convention on the Law of the Sea)

- agriculture (e.g. International Convention for the Protection of Plants).

Despite successes on the continent, there is still great concern for the general lack of change in cultural practices and attitudes towards the environment. Policy responses need to consider the finite nature of natural resources and the future implications of current government actions (and inactions). Policy-makers need to look forward, contemplating the interrelationship between human-driven development and the environment, and approach policy design in a fundamentally new way. They should see environmental issues as opportunities for development rather than as limitations

\section{Reflections on policy response challenges}

Based on a robust analysis of literature dealing with sustainable development on the continent, the following policy response challenges became evident:

- Distribution challenges: that is, equitably distributing benefits emanating from government programmes; suitable approaches, methods and mechanisms for distribution of goods and services.

- Governance and macro-economic challenges: that is, establishing good governance practices, structures and systems to promote economic growth; creating a conducive macro-economic policy framework.

- Capacity challenges: that is, the ability of the state to successfully translate policy intent into policy action by means of adequate infrastructure, people skills, government apparatus and resources.

- Participation challenges: that is, civil society engagement and input into policy-making processes; establishing appropriate mechanisms for participation; creating a governance culture of openness, access to information and transparency; ensuring legitimacy of government policies and that the community takes ownership of development programmes and projects.

- Facilitating or intervention challenges: that is, ideologies regarding state interventions in the economy (e.g. developmental state) versus liberal, market-driven (free) economy informing policy design.

- Policy analyses challenges: that is, the ability of policymakers to consider potential unintended consequences of policies. An example in this regard is the recent policy issued by the Department of Foreign Affairs in South Africa whereby all visitors to the country under the age of 18 must have a detailed birth certificate, as well as the written consent of both parents. This had major negative consequences for the tourist industry.

- Policy M\&E challenges: that is, the capacity of policymakers to monitor policy implementation and to evaluate its output, outcomes and impact. This requires pre-policy and post-policy intervention statistics. It also implies the availability, reliability, validity and accuracy of policy intervention data.

To this list of challenges, one may add the general lack of policy coherence on the continent. Because of the complexities associated with this challenge, it is dealt with in a separate section below.

\section{Building policy coherence on the continent}

As stated above, the interrelatedness of policy dimensions, the need for transgovernance and the fact that a multitude of actors are involved make the improvement of policy coherence (i.e. alignment between regional, national and local levels, coordination, and agency cooperation) a critical success factor. National governments have to respond by making their structures and systems of governance more agile and adaptable to new realities. Furthermore, rigid and cumbersome policy-making processes need to become more flexible to rapidly respond to immediate and emerging environmental crises.

Probably the biggest stumbling block as far as policy coherence is concerned is the fact that the geo-political, geo-spatial and demographical realities differ vastly on the continent. Reaching consensus on the 'best' approach to deal with a particular issue is therefore not easy. Furthermore, different cultures, language and belief systems, political ideology and systems of governance complicate matters. Other challenges as far as coherence is concerned include the following:

- reconciling domestic priorities with continental concerns

- adhering to multilateral trade agreements and other arrangements

- aligning the need for central control (e.g. the AU) versus the decentralised actions taken by individual countries

- fragmenting of policy responses between countries

- pinpointing responsibility for certain actions because of the variety of actors (e.g. public, private and third sectors)

- conflict between groups within countries (e.g. civil war) and even military conflict between countries on the continent complicate policy agreement

- establishing a governance culture of transparency and openness between governance apparatus in countries

- utilising technology optimally for information dissemination and monitoring and policy oversight

- relatively low educational levels of the general populace of the continent to adequately participate in policy initiatives. 
The establishment of coordination mechanisms on continental, regional and national scales is crucial to foster policy coherence. These mechanisms, such as coordinating committees, conventions and protocols, should promote factbased, rational decision-making. These mechanisms should also enable careful analyses of all the options available, the cost-effectiveness of each potential policy response, the identification of potential policy conflicts and the long-term impact of policies. The establishment of data and information systems, as well as analytical capability, is essential in this regard. Mechanisms should also disseminate best practice, uncover lessons learned and foster dialogue between different policy-makers.

Metcalfe (1996:41-43) in this regard makes a significant contribution by proposing the following steps that should be followed on different levels on the continent to ensure policy coherence within and between countries:

- Step 1: Ministries within each country should make independent policy decisions based on its unique circumstances and maintain its autonomy within its own policy domain such as health, safety and education.

- Step 2: Exchange of policy ideas with other ministries in the same government and with similar ministries in other countries. Intergovernmental coordination and alignment are necessary since many development challenges are multidimensional. This means, for example, that the Ministry of Foreign Affairs should consult the Ministry of Tourism to ensure policy coherence. At the same time, extra-governmental coordination is necessary to ensure that the Ministry of Foreign Affairs in Botswana, for example, more or less synchronises its policy response with that of neighbouring countries such as Zambia and Namibia. Such exchange of policy ideas is crucial to keep each other up to date about emerging trends and issues and also how they suggest should be acted upon it. This exchange of policy-related information often leads to ministries adjusting their original policy response.

- Step 3: Working towards policy convergence among ministries. In order to 'speak with one voice' it is imperative that the respective ministries do not take divergent policy positions on a particular matter. Such divergences should not be revealed to the public since it is necessary to show that the continent takes a common stance on sustainable development matters. It is therefore necessary that the ministries search for consensus and agreement. In cases where divergent opinions lead to conflict among ministries, it is important to have arbitration and conciliation mechanisms in place. There should be a relationship of mutual trust among all parties concerned and confidence in the abilities of each ministry. It should be noted, however, that although a common position is stated, each ministry may implement the policy in a unique manner, taking into consideration the particular circumstances and severity of a particular development issue in the country. Each country thus remains autonomous as far as the execution of policies is concerned. The policy should set the broad parameters and strategic framework within which each country can decide how to respond - in line with its own priorities, capacities and national development plan.

\section{Conclusion}

The purpose of this article was to analyse the nature and scope of development policy influencing Africa's policy responses to sustainable development challenges. It is evident that challenges associated with sustainable development transcend national borders. This requires a far more coherent and coordinated policy response. It is further clear that across Africa there have been varied policy responses to sustainable development challenges. Despite successes on the continent, inclusive of the establishment of various sectoral policy frameworks and coordinating mechanisms, there is still great concern for the general lack of a coordinated response to environmental concerns.

Further empirical research should be conducted to determine the respective contributions of individual country's policymaking intend and processes and to place the African continent on a more sustained growth trajectory. This trajectory is currently strained by the lack of transgovernance and other challenges such as national interests, regional conflict, state corruption and the general absence of sustainable development policy coherence. Such policy coherence should be directed not only by country-specific development concerns, but also by bilateral and trilateral consensus between regional and continental partnerships to address pressing challenges associated with sustainable development.

\section{Acknowledgements Competing interests}

The authors have declared that no competing interest exists.

\section{Author's contributions}

All authors contributed equally to this work.

\section{Ethical consideration}

This article followed all ethical standards for carrying out research.

\section{Funding information}

This research received no specific grant from any funding agency in the public, commercial or not-for-profit sectors.

\section{Data availability statement}

Data sharing is not applicable to this article as no new data were created or analysed in this study.

\section{Disclaimer}

The views and opinions expressed in this article are those of the authors and do not necessarily reflect the official policy or position of any affiliated agency of the authors. 


\section{References}

African Environmental Outlook, 2006, Our environment, our wealth, United Nations Environment, viewed 12 August 2019, from http://wedocs.unep.org/handle/ 20.500.11822/9626.

Anderson, J.E., 2000, Public policy making, Houghton Mifflin, Boston, MA.

Arusha, 1990, Arusha charter on popular participation in development and transformation, viewed 22 August 2019, from https://oldsite.issafrica.org/ uploads/popularppartcharter.pdf.

Birkland, T.A., 2005, An introduction to the policy process: Theories, concepts and models of public policy making, Routledge, London.

Brauch, H.G. (ed.), 2002, Facing global environmental change, Springer-Verlag, Heidelberg.

Chibber, V., 2014, 'The developmental state in retrospect and prospect: Lessons from India and South Korea', in M. Williams (ed.), The end of the developmental state?, pp. 30-54, Routledge, New York, NY.

Driscoll, R., Agha, Z.K., Cali, M. \& Te Velde, D.W., 2007, Growth and trade in Africa's second generation poverty reduction strategies, Overseas Development Institute, London.

Dye, T.R., 1995, Understanding public policy, 7th edn., Prentice-Hall, Englewood Cliffs, NJ.
Grin, J., Rotmans, J. \& Schot, J., 2010, Transitions to sustainable development: New directions in the study of long term structural change, Routledge, New York, NY.

Kerbo, H., 2006, World poverty in the 21st century, McGraw-Hill, New York, NY.

Meadowcroft, J., 2007, 'Who is in charge here? Governance for sustainable development in a complex world', Journal of Environmental Policy and Planning 9(3), 299-314. https://doi.org/10.1080/15239080701631544

Metcalfe, L., 1996, 'Building capacities for integration: The future role of the Commission', viewed n.d., from http://aei.pitt.edu/827/1/1.htm.

Moran, M., Rein, M. \& Goodin, R.E. (eds.), 2008, The oxford handbook of public policy, Oxford University Press, Oxford.

Purvis, B., Mao, Y. \& Darren, R., 2018, 'Three pillars of sustainability: In search of conceptual origins', Sustainability Science 14(3), 681-695. https://doi. org/10.1007/s11625-018-0627-5

Scooner, I., 1998, 'Sustainable rural livelihoods: A framework for analysis', IDS working paper, IDS, Addis Ababa.

Stone, D., 2001, Policy paradox: The art of political decision making, WW Norton, New York, NY.

Sustainability Transitions Research Network (STRN), 2009, A mission statement and research agenda for the sustainability transitions research network viewed 23 August 2019, from http://www.transitionsnetwork.org/files/ STRNresearchagenda20August2010\%282\%29.pdf.

Voß, J-B., Bauknecht, D. \& Kemp, R. (eds.), 2006, Reflexive governance for sustainable development, Edward Elgar, Cheltenham. 